\title{
Causes and timing of future biosphere extinctions
}

\author{
S. Franck, C. Bounama, and W. von Bloh \\ Potsdam Institute for Climate Impact Research, Potsdam, Germany \\ Received: 28 September 2005 - Published in Biogeosciences Discuss.: 7 November 2005 \\ Revised: 25 January 2006 - Accepted: 26 January 2006 - Published: 10 March 2006
}

\begin{abstract}
We present a minimal model for the global carbon cycle of the Earth containing the reservoirs mantle, ocean floor, continental crust, biosphere, and the kerogen, as well as the combined ocean and atmosphere reservoir. The model is specified by introducing three different types of biosphere: procaryotes, eucaryotes, and complex multicellular life. During the entire existence of the biosphere procaryotes are always present. $2 \mathrm{Gyr}$ ago eucaryotic life first appears. The emergence of complex multicellular life is connected with an explosive increase in biomass and a strong decrease in Cambrian global surface temperature at about $0.54 \mathrm{Gyr}$ ago. In the long-term future the three types of biosphere will die out in reverse sequence of their appearance. We show that there is no evidence for an implosion-like extinction in contrast to the Cambrian explosion. In dependence of their temperature tolerance complex multicellular life and eucaryotes become extinct in about $0.8-1.2 \mathrm{Gyr}$ and $1.3-1.5 \mathrm{Gyr}$, respectively. The ultimate life span of the biosphere is defined by the extinction of procaryotes in about $1.6 \mathrm{Gyr}$.
\end{abstract}

\section{Introduction}

The general basis of this paper is the long-term evolution of the global carbon cycle from the Archaean up to about $2 \mathrm{Gyr}$ into the future and its consequences for the Earth's climate and the biosphere. In particular, we investigate the influence of geosphere-biosphere interactions on the life span of the biosphere. The problem of the long-term existence of the biosphere was first discussed by astrophysicists. They analysed increase of insolation during Sun's evolution on the main sequence. Already in the 1960s, Unsöld (1967) predicted the ultimate end of terrestrial life in about $3.5 \mathrm{Gyr}$ when solar luminosity will be about $40 \%$ higher than now and temperatures at the Earth's surface will be above the

Correspondence to: C. Bounama

(bounama@pik-potsdam.de) boiling-point of water. Within the framework of Earth system science (Franck et al., 2000, 2002) our planet is described as a system of certain interacting components (mantle, oceanic crust, continental lithosphere, atmosphere, hydrosphere, and biosphere) that develops under increasing external forcing (increasing insolation) and changing internal forcing (decreasing spreading rate, growing continental area). Within certain limits the Earth system is able to self-regulate against changing external and internal forcing. The life span of the biosphere is related to these limits of self-regulation. Lovelock and Whitfield (1982) published the first estimations of the biosphere's life span. According to their semi-quantitative model, photosynthesis ceases already in about $100 \mathrm{Myr}$ because the atmospheric carbon dioxide content falls below the minimum value for $\mathrm{C} 3$-plants $(150 \mathrm{ppm})$. The first quantitative model for the long-term future of the biosphere was proposed by Caldeira and Kasting (1992). With the help of a more sensitive climate model and under the assumption of a minimum atmospheric $\mathrm{CO}_{2}$ value of $10 \mathrm{ppm}$ for C4-plants, they calculated that the biosphere's life span extends up to about $800 \mathrm{Myr}$. Franck et al. (2000) developed an Earth system model that takes into account quantitatively the internal forcing by geodynamics. This effect results in a reduction of the biosphere life span from $800 \mathrm{Myr}$ to $600 \mathrm{Myr}$. The biotic enhancement of weathering and its influence on the life span was investigated by Lenton and von Bloh (2001). According to their results the current biosphere should remain resilient to carbon cycle perturbation or mass extinction events for at least $800 \mathrm{Myr}$ and may survive for up to $1.2 \mathrm{Gyr}$. The question of the life span of the biosphere is also connected to the question of the fate of the Earth's ocean. Bounama et al. (2001) have shown that liquid water will be always available in the surface reservoirs as a result of internal processes. The extinction of the biosphere will not be caused by the catastrophic loss of water but by other limiting factors caused by the external forcing of increasing solar luminosity.

Published by Copernicus GmbH on behalf of the European Geosciences Union. 
All these estimations of the biosphere life span deal with a rather simple unique biosphere existing within a certain temperature tolerance window and above a certain minimum value of atmospheric $\mathrm{CO}_{2}$ content. A natural extension to a more specific biosphere is to introduce three types of biosphere (procaryotes, eucaryotes, complex multicellular life) with different temperature tolerance windows and different biotic enhancement of weathering. According to Ward and Brownlee (2002) the long-term future of the biosphere is in some sense a mirror image of the history: the different biosphere types will become extinct in reverse sequence of their appearance.

In the present paper we apply our general model for the long-term co-evolution of the geosphere and the biosphere (Franck et al., 2002) with three different biosphere pools (procaryotes, simple eucaryotes, and complex multicellular life) to investigate the long-term evolution of the biosphere. Our model was previously used to investigate the Cambrian explosion as triggered by geosphere-biosphere feedbacks (von Bloh et al., 2003). We found that the Cambrian explosion was mainly driven by extrinsic environmental causes and so rapid because of a positive feedback between the spread of biosphere, increased silicate weathering, and a consequent cooling of the climate.

The main questions to be answered in the following are: What are the life spans of the three different types of biosphere and what are the reasons for their extinction?

\section{Model description}

The global carbon cycle model of Franck et al. (2002) describes the evolution of the mass of carbon in the mantle, $C_{m}$, in the combined reservoir consisting of ocean and atmosphere, $C_{o+a}$, in the continental crust, $C_{c}$, in the ocean crust and floor, $C_{f}$, in the kerogen, $C_{\mathrm{ker}}$, and in the different biospheres, $C_{\mathrm{bio}, i}(i=1, \ldots, n)$, where $n$ is the number of the distinct parameterized biosphere types. The equations for the efficiency of carbon transport between reservoirs take into account mantle de- and regassing, carbonate precipitation, carbonate accretion, evolution of continental biomass, the storage of dead organic matter, and weathering processes.

$$
\begin{aligned}
\frac{\mathrm{d} C_{m}}{d t}= & \tau_{f}^{-1}(1-A) R C_{f}-S_{A} f_{c} d_{m} C_{m} / V_{m} \\
\frac{\mathrm{d} C_{o+a}}{d t}= & \tau_{f}^{-1}(1-A)(1-R) C_{f}+S_{A} f_{c} d_{m} C_{m} / V_{m}+ \\
& +F_{\mathrm{weath}}\left(C_{o+a}, C_{c}\right)+(1-\gamma) \sum_{i=1}^{n} \tau_{\mathrm{bio}, i}^{-1} C_{\mathrm{bio}, i}+\tau_{\mathrm{ker}}^{-1} C_{\mathrm{ker}}- \\
& -\sum_{i=1}^{n} \Pi_{i}\left(C_{o+a}\right)-F_{\mathrm{prec}}\left(C_{o+a}, C_{c}\right)-F_{\mathrm{hyd}}
\end{aligned}
$$$$
\frac{\mathrm{d} C_{c}}{d t}=\tau_{f}^{-1} A C_{f}-F_{\text {weath }}\left(C_{o+a}, C_{c}\right)
$$

$$
\begin{gathered}
\frac{\mathrm{d} C_{f}}{d t}=F_{\mathrm{prec}}\left(C_{o+a}, C_{c}\right)+F_{\mathrm{hyd}}-\tau_{f}^{-1} C_{f} \\
\frac{\mathrm{d} C_{\mathrm{bio}, 1}}{\mathrm{~d} t}=\Pi_{1}\left(C_{o+a}\right)-\tau_{\mathrm{bio}, 1}^{-1} C_{\mathrm{bio}, 1} \\
\vdots \\
\frac{\mathrm{d} C_{\mathrm{bio}, n}}{\mathrm{~d} t}=\Pi_{n}\left(C_{o+a}\right)-\tau_{\mathrm{bio}, n}^{-1} C_{\mathrm{bio}, n} \\
\frac{\mathrm{d} C_{\mathrm{ker}}}{\mathrm{d} t}=\gamma \sum_{i=1}^{n} \tau_{\mathrm{bio}, i}^{-1} C_{\mathrm{bio}, i}-\tau_{\mathrm{ker}}^{-1} C_{\mathrm{ker}}
\end{gathered}
$$

The variable $t$ is the time, $\tau_{f}$ the residence time of carbon in the seafloor, $A$ the accretion ratio of carbon, $R$ the regassing ratio, $S_{A}$ the areal spreading rate, $f_{c}$ the degassing fraction of carbon, $d_{m}$ the melt generation depth, $V_{m}$ the mantle volume, $F_{\text {weath }}$ the weathering rate, $F_{\text {prec }}$ the rate of carbonate precipitation, $F_{\text {hyd }}$ the hydrothermal flux, $\gamma$ the fraction of dead biomass transferred to the kerogen, $\tau_{\text {bio }, i}$ the residence time of carbon in the type $i$ biosphere, $\Pi_{i}$ the total productivity of the type $i$ biosphere, and $\tau_{\mathrm{ker}}$ is the residence time of carbon in the kerogen. The accretion ratio, $A$, is defined as the fraction of seafloor carbonates accreted to the continents to the total seafloor carbonates. The regassing ratio, $R$, is defined as the fraction of seafloor carbonates regassed into the mantle to the total subducting carbonates. $S_{A}$ and $d_{m}$ are calculated from a parameterized thermal evolution model of whole mantle convection including the water exchange between mantle and surface reservoirs (Franck and Bounama, 1995). The box model including the pertinent fluxes is sketched in Fig. 1.

\subsection{Climate modelling}

In order to calculate the surface temperature, $T_{s}$, we need a climate model, which links the temperature to the given partial pressure of atmospheric $\mathrm{CO}_{2}$ and the solar constant, $S$. We apply the grey atmosphere model of Lenton (2000). The temperature is determined using energy balance between the incoming and outgoing radiation:

$\sigma T_{s}^{4}=\frac{(1-a) S}{4}\left(1+\frac{3}{4} \tau\right)$,

where $\sigma$ is the Stefan-Boltzmann constant, $a$ is the average planetary albedo, and $\tau$ is the vertical opacity of the greenhouse atmosphere. The opacities of the two greenhouse gases, $\mathrm{CO}_{2}$ and $\mathrm{H}_{2} \mathrm{O}$, are assumed to be independent from each other:

$\tau=\tau\left(p_{\mathrm{CO}_{2}}\right)+\tau\left(p_{\mathrm{H}_{2} \mathrm{O}}\right)$.

The opacity of $\mathrm{CO}_{2}$ is assumed to be a function of its mixing ratio. It is derived from the results of varying $\mathrm{CO}_{2}$ in a radiative-convective climate model (Kasting et al., 1993). 


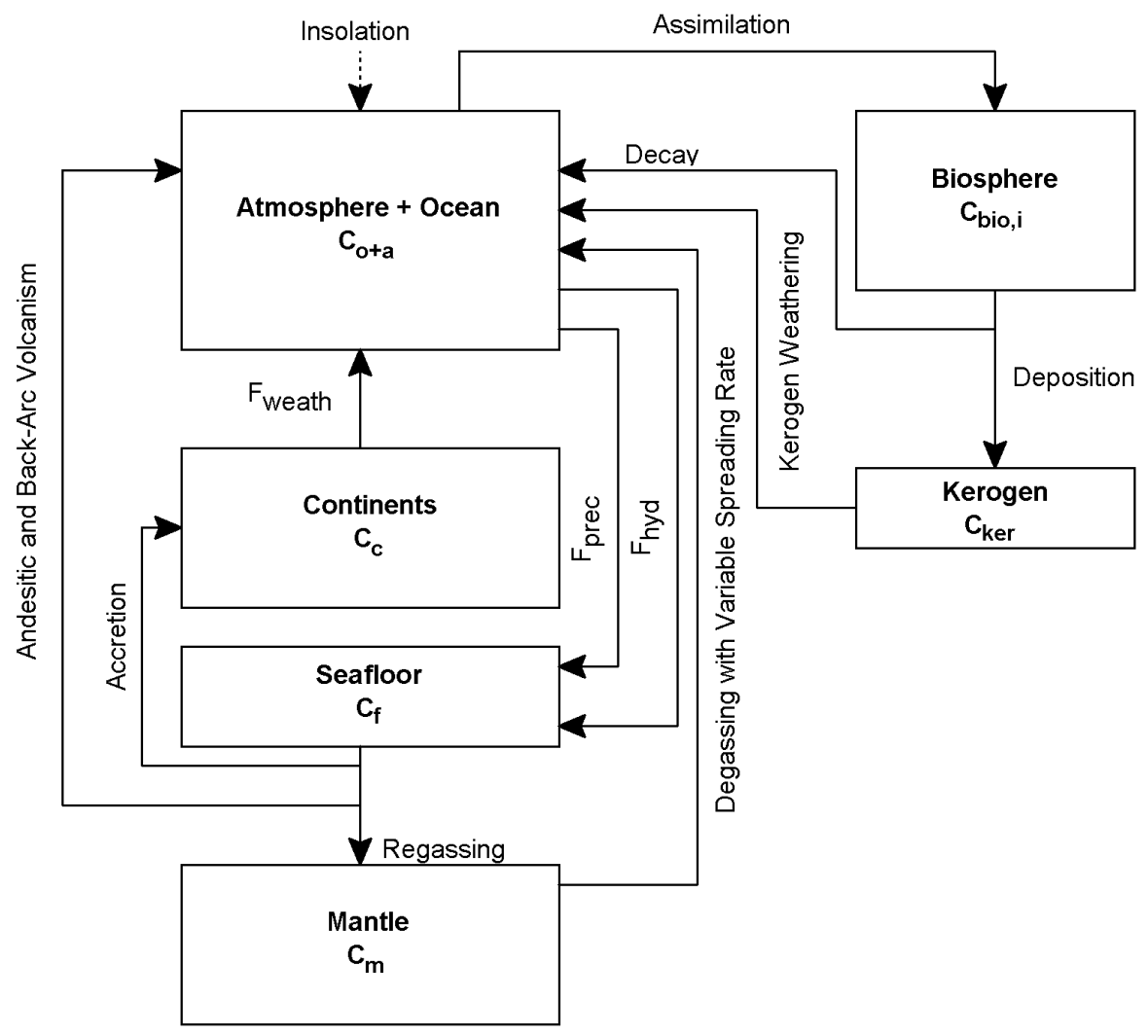

Fig. 1. Diagram illustrating the basic mechanisms and interactions of the global carbon cycle. The fluxes from and to the different pools are indicated by arrows.

The partial pressure of $\mathrm{H}_{2} \mathrm{O}, p_{\mathrm{H}_{2} \mathrm{O}}$, can be expressed as a function of temperature and relative humidity, $H$, using the Clausius-Clapeyron equation. Here we use a wet greenhouse model with $H=1$ (full saturation). The partial pressure of $\mathrm{CO}_{2}, p_{\mathrm{CO}_{2}}$, can be calculated from the $C_{o+a}$ reservoir under the condition of equal partial pressures of $\mathrm{CO}_{2}$ at the interface between atmosphere and ocean (Franck et al., 2002). The solar constant evolves according to Caldeira and Kasting (1992).

Our climate model depends only on the brightening Sun and the $\mathrm{CO}_{2} / \mathrm{H}_{2} \mathrm{O}$ greenhouse effect. Therefore, we neglect so-called anti-greenhouse effects that potentially cool the planet: sulfuric acid aerosols, hydrocarbon stratospheric hazes, ice-albedo feedbacks, and clouds.

\subsection{Weathering rates}

There are two main types of weathering processes: silicate weathering and carbonate weathering. Both types are enhanced by the biosphere. First, there is an increase of soil $\mathrm{CO}_{2}$ partial pressure due to respiration of soil organisms and due to the respiration from the roots of vascular plants. Furthermore, there is an additional direct dependence of weathering on biological productivity (due to the secretion of organic acids, chelating agents, etc.) by a factor $\beta$ mediating the carbonate and silicate weathering rate, $F_{\text {weath }}^{c}$ and $F_{\text {weath }}^{s}$, respectively:

$F_{\text {weath }}^{c}=\beta \cdot f_{\text {weath }}^{c}$,

$F_{\text {weath }}^{s}=\beta \cdot f_{\text {weath }}^{s}$,

where $f_{\text {weath }}^{c, s}$ denote the original carbonate and silicate weathering rate without additional biotic enhancement. The prefactor $\beta$ reflects the biotic enhancement of weathering by the biosphere types, $i$ :

$\beta=\prod_{i=1}^{n}\left(\frac{1}{\beta_{i}}+\left(1-\frac{1}{\beta_{i}}\right) \frac{\Pi_{i}}{\Pi_{i}^{*}}\right)$.

The factor $\beta_{i}$ denotes the specific biotic amplification of weathering, $\Pi_{i}$ the specific biological productivity, and $\Pi_{i}^{*}$ the respective present-day value of biosphere type $i$. In our study as a first approximation we considered a biotic enhancement of weathering only by complex multicellular life $\left(\beta_{1}=\beta_{2}=1, \beta_{3}>1\right)$. According to Schwartzman (1999, Figs. 8-3) complex multicellular life contributes about 7 times more to the biotic enhancement of weathering than primitive life. 
Table 1. Model constants for the three different biosphere types: (1) procaryotes, (2) eucaryotes, (3) complex multicellular life. Case 1 denotes the restrictive temperature tolerance windows given by von Bloh et al. (2003), while case 2 denotes the values given by Schwartzman (1999).

\begin{tabular}{lcccccc}
\hline Biosphere type & $i=1$ & $\begin{array}{c}\text { Case } 1 \\
i=2\end{array}$ & $i=3$ & $i=1$ & $\begin{array}{c}\text { Case } 2 \\
i=2\end{array}$ & $i=3$ \\
\hline$T_{\min }\left({ }^{\circ} \mathrm{C}\right)$ & 2 & 5 & 0 & 0 & 0 & 0 \\
$T_{\max }\left({ }^{\circ} \mathrm{C}\right)$ & 100 & 45 & 30 & 100 & 60 & 45 \\
$\Pi_{\max }(\mathrm{Gt} / \mathrm{yr})$ & 20 & 20 & 20 & 20 & 20 & 20 \\
$P_{\min }\left(10^{-6}\right.$ bar $)$ & 10 & 10 & 10 & 10 & 10 & 10 \\
$P_{1 / 2}\left(10^{-6}\right.$ bar $)$ & 210.8 & 210.8 & 210.8 & 210.8 & 210.8 & 210.8 \\
$\tau_{\text {bio }}(\mathrm{yr})$ & 12.5 & 12.5 & 12.5 & 12.5 & 12.5 & 12.5 \\
$\beta$ & 1 & 1 & 3.6 & 1 & 1 & 17.5 \\
\hline
\end{tabular}

\subsection{Biological productivity}

In our model the biological productivity is based on photosynthetic activity and depends on the mean global surface temperature, $T_{s}$, and on the $\mathrm{CO}_{2}$ partial pressure of the atmosphere, $p_{\mathrm{CO}_{2}}$ :

$\Pi_{i}=\Pi_{\max , i} f_{T_{s, i}}\left(T_{s}\right) f_{\mathrm{CO}_{2}, i}\left(p_{\mathrm{CO}_{2}}\right)$,

where $\Pi_{\max , i}$ is the maximum productivity of biosphere type $i$. The values for $\tau_{\text {bio }, i}$ and $\Pi_{\max , i}$ have been adjusted to yield the present day distribution of biomass among the three different pools. The function describing the temperature dependence, $f_{T s, i}$, is parameterized by a parabola:

$f_{T_{s}, i}\left(T_{s}\right)=1-\frac{\left(T_{s}-T_{\min , i}\right)\left(T_{\max , i}-T_{s}\right)}{4\left(T_{\max , i}-T_{\min , i}\right)^{2}}$

and the function for the $p_{\mathrm{CO}_{2}}$ dependence is a MichaelisMenten hyperbola:

$f_{\mathrm{CO}_{2}, i}\left(p_{\mathrm{CO}_{2}}\right)=\frac{p_{\mathrm{CO}_{2}}-p_{\min , i}}{p_{1 / 2, i}+p_{\mathrm{CO}_{2}}-p_{\min , i}}$.

$p_{\text {min }, i}$ denotes the minimum $\mathrm{CO}_{2}$ atmospheric partial pressure allowing photosynthesis of biosphere type $i$. $p_{1 / 2, i}+p_{\min , i}$ is the pressure resulting a productivity half its maximum value. The interval $\left[T_{\min , i \ldots} T_{\max , i}\right]$ denotes the temperature tolerance window. It must be emphasized that this window is related to the mean global surface temperature. If the global surface temperature is inside this window a global abundance of biosphere type $i$ is possible. Our parameterization of the biological productivity is based on oxygenic photosynthesis. In this study we investigated two different cases: first we applied the more restrictive tolerance windows given by von Bloh et al. (2003) and second the values given by Schwartzman (1999). He defines physiological tolerances for local temperatures of different organisms, which are $15^{\circ} \mathrm{C}$ to $20^{\circ} \mathrm{C}$ higher than ours. The explicit values are given in Table 1.

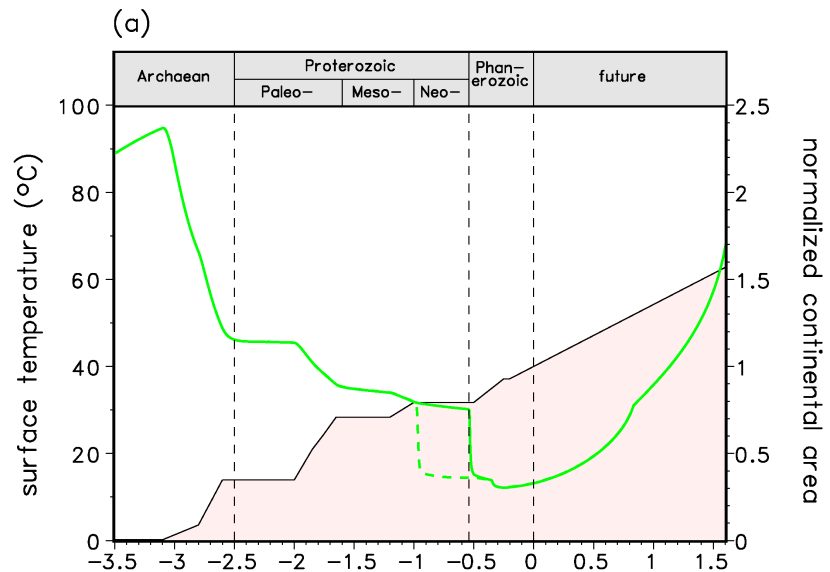

(b)

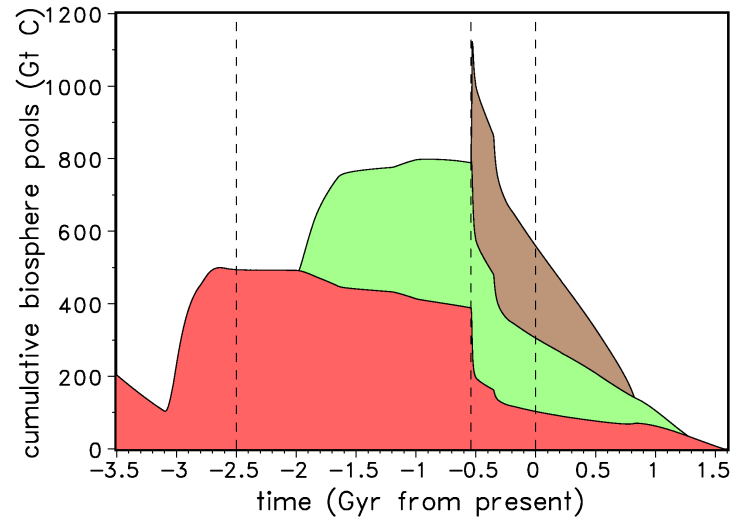

Fig. 2. Case 1, (a) Evolution of global surface temperature (solid green line). The green dashed line denotes a second possible evolutionary path triggered by a temperature perturbation in the Neoproterozoic era. The coloured area indicates the evolution of the normalized continental area according to Condie (1990). (b) Evolution of the cumulative biosphere pools for procaryotes (red), eucaryotes (green), and complex multicellular life (brown).

\section{Results and discussion}

The global carbon cycle model given in Eqs. (1-6) has been solved numerically for three biosphere types: procaryotes, simple eucaryotes (protista), and complex multicellular life. The model runs have been performed for two cases: temperature tolerances (case 1) given by von Bloh et al. (2003) and (case 2) given by Schwartzman (1999). The corresponding parameters for the biospheres are summarized in Table 1. All other parameters have been taken from Franck et al. (2002) for the favoured model with spreading dependent hydrothermal flux and constant $\mathrm{pH}$ of the ocean. The biotic enhancement factor $\beta_{3}$ has been adjusted in such a way that complex multicellular life appears spontaneously first at $-542 \mathrm{Myr}$. We derived $\beta_{3}=3.6$ in case 1 and $\beta_{3}=17.5$ in case 2 .

In Fig. 2a we have plotted the results of case 1 for the evolution of the mean global surface temperature from the Archaean to the long-term future in about 2 Gyr. Estimations 
of Precambrian palaeotemperatures date back to the early Archaean and are based on oxygen isotopic composition of cherts (Knauth and Lowe, 2003). According to these data, the ocean surface water has cooled from $70^{\circ} \mathrm{C}\left( \pm 15^{\circ} \mathrm{C}\right)$ in the Archaean ocean to the present value. Such values are conceivable as mean global surface temperatures during the early Archaean when atmospheric $\mathrm{CO}_{2}$ levels could have been very high (Franck et al., 2002). Nevertheless, high Archaean temperatures from the oxygen isotopic composition of cherts are still controversial (Sleep and Hessler, 2006). In our model high Archaean atmospheric $\mathrm{CO}_{2}$ levels are caused by two effects: first there is only a small amount of continental area for weathering (reduced sink of atmospheric $\mathrm{CO}_{2}$ ) and second there is an intense volcanic outgassing due to higher geodynamic activity (elevated source of atmospheric $\mathrm{CO}_{2}$ ).

In Fig. $2 b$ we show the corresponding cumulative biosphere pools. The question of how much biomass exists at different stages in the Earth's evolution is of great importance for our modelling. The problem of the quantitative evolution of the terrestrial biomass through time is a question of scientific and practical concern, because fossil organic carbon is the prime energy source of the present society (Schidlowski, 1991). During the entire existence of the biosphere procaryotes are always present. 2 Gyr ago eucaryotic life first appears because the global surface temperature reaches the tolerance window for eucaryotes. This moment correlates with the onset of a rapid temperature drop caused by increasing continental area. The resulting increase in the weathering flux takes out $\mathrm{CO}_{2}$ from the atmosphere. In contrast to the eucaryotes the first appearance of complex multicellular life starts with an explosive increase in biomass connected with a strong decrease in Cambrian global surface temperature at about $0.54 \mathrm{Gyr}$ ago. The biological colonization of land surface by metaphyta and the consequent increase in silicate weathering rates caused a reduction in atmospheric $\mathrm{CO}_{2}$ and planetary cooling. After the Cambrian explosion there is a continuous decrease of biomass in all pools. At $0.35 \mathrm{Gyr}$ ago there is a slight drop in all biomass pools connected with the rise of vascular plants. The continuous decrease in biomass of primitive life forms (procaryotes and eucaryotes) since the Cambrian explosion is related to the fact that Phanerozoic surface temperatures are below the optimum for these life forms. The decrease in biomass of complex life forms is due to the fact that there is a continuous decrease in Phanerozoic atmospheric carbon content. At present the biomass is almost equally distributed between the three pools and the mean global surface temperature of about $15^{\circ} \mathrm{C}$ is near the optimum value for complex multicellular life.

In the future we can observe a further continuous decrease of biomass with the strongest decrease in the complex multicellular life. The life spans of complex multicellular life and of eucaryotes end at about $0.8 \mathrm{Gyr}$ and $1.3 \mathrm{Gyr}$ from present, respectively. In both cases the extinction is caused by reaching the upper limit of the temperature tolerance window. In

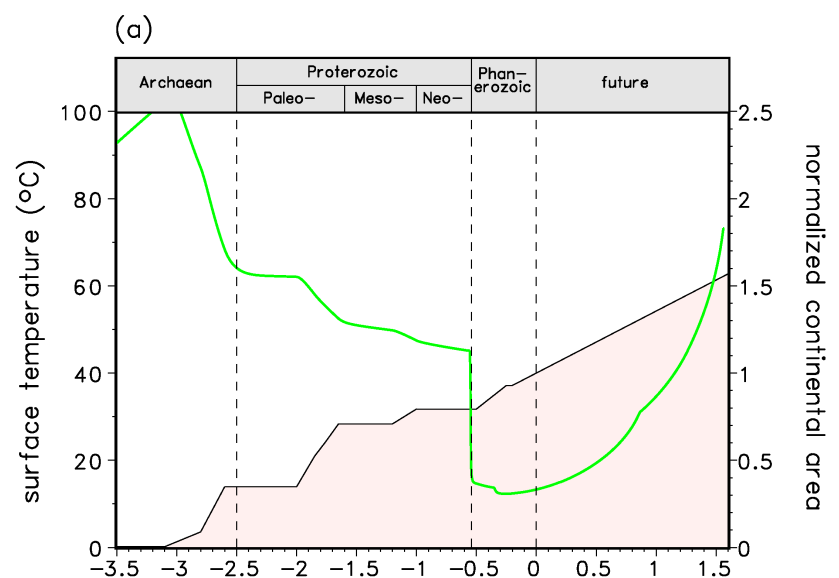

(b)

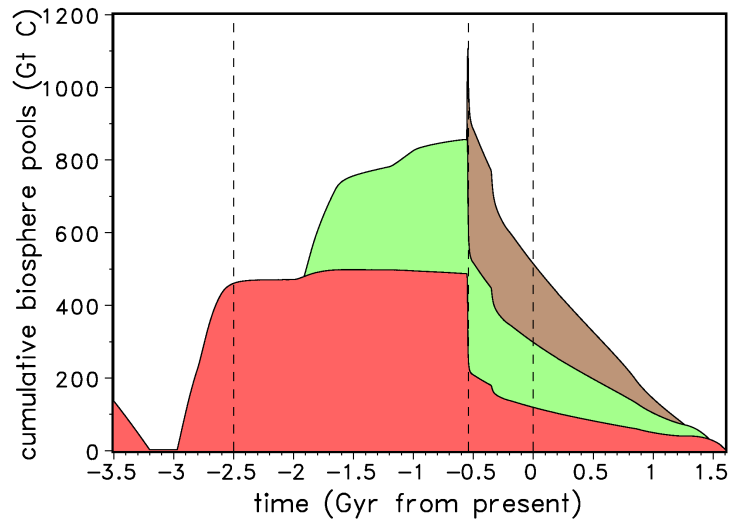

Fig. 3. Case 2, (a) Evolution of global surface temperature (solid green line). The coloured area indicates the evolution of the normalized continental area according to Condie (1990). (b) Evolution of the cumulative biosphere pools for procaryotes (red), eucaryotes (green), and complex multicellular life (brown).

contrast to the first appearance of complex multicellular life via the Cambrian explosion, its extinction proceeds more or less continuously.

In Fig. 3 we have plotted the results of case 2 for the evolution of the mean global surface temperature and the cumulative biosphere pools from the Archaean to the long-term future in about $2 \mathrm{Gyr}$. There are no qualitative differences to case 1. In particular, the Cambrian explosion event is even more pronounced and the three biosphere types cease to exist in the same way. Complex multicellular life becomes extinct in about $1.2 \mathrm{Gyr}$ and eucaryotes in about $1.5 \mathrm{Gyr}$.

In both cases the ultimate life span of the biosphere, i.e. the extinction of procaryotes, ends at about $1.6 \mathrm{Gyr}$. In this case the extinction is not caused by the temperature leaving the tolerance window but by a too low atmospheric $\mathrm{CO}_{2}$ content for photosynthesis.

In Fig. 4 we have plotted for case 1 the time when the different life forms appear and disappear and the time interval in which perturbations may trigger the first emergence and the extinction of complex life prematurely as a function of 


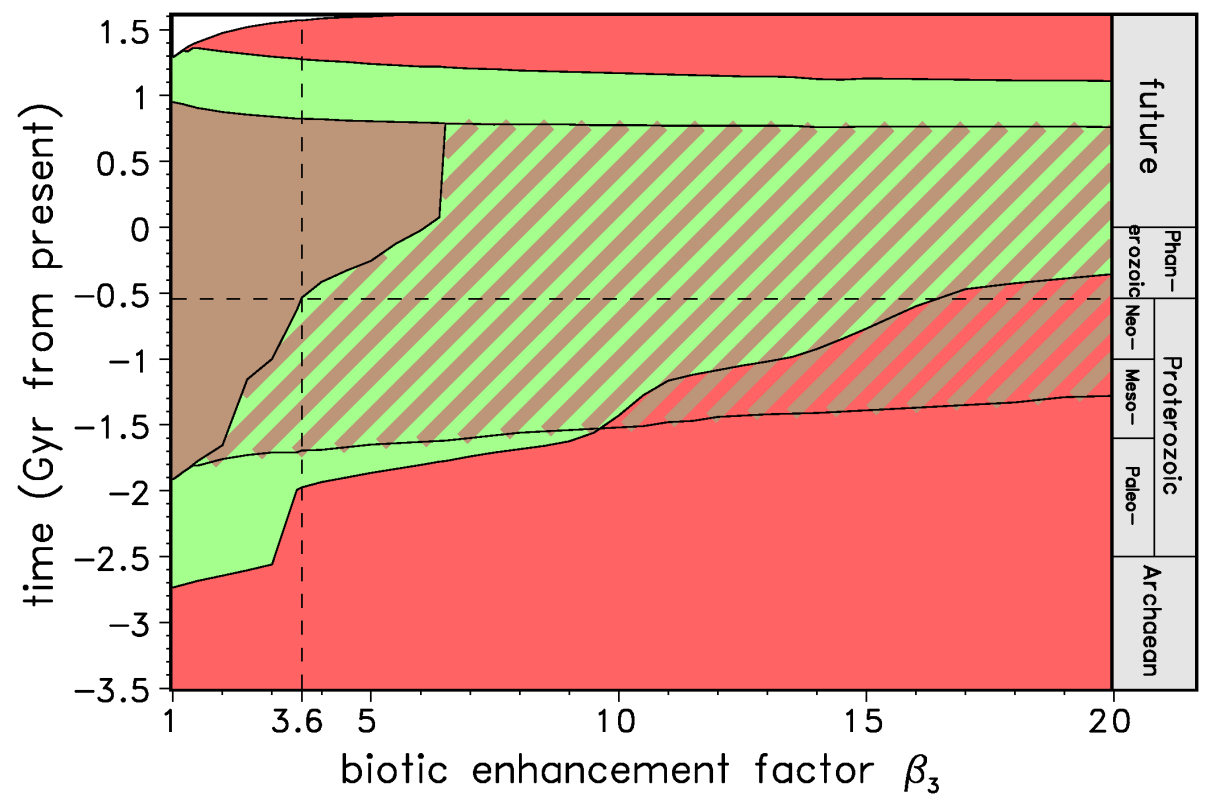

Fig. 4. Stability diagram for the three types of biosphere (case 1) as a function of the biotic enhancement factor, $\beta_{3}$. In the red area only procaryotic life exists while in the green area eucaryotic and procaryotic life coexist. In the brown area complex multicellular life appears additionally. The dashed area indicates the time interval in which a perturbation may trigger the first emergence or extinction of complex multicellular life prematurely. The horizontal dashed line denotes the time of the Cambrian explosion. The vertical dashed line denotes the corresponding value of $\beta_{3}$.

the biotic enhancement factor $\beta_{3}$. Up to $-1.75 \mathrm{Gyr}$ there is only a unique solution (no bistability). Therefore, the Huronian glaciations circa $2.4 \mathrm{Gyr}$ ago cannot trigger a prematurely emergence of eucaryotic or even complex life. On the other hand, Neoproterozoic snowball Earth events have the potential to initiate an earlier appearance of complex life forms. However, these global glaciations are followed by a global hothouse (Hoffman and Schrag, 2002) that immediately pushes the temperatures again above the upper tolerance limit. In the case of $\beta_{3}=3.6$ complex multicellular life could appear in principle at $1.7 \mathrm{Gyr}$ ago. There is evidence for small metazoans and multicellular algae well before the Ediacarans (appeared $600 \mathrm{Myr}$ ago), but they had no influence on weathering and possibly a higher temperature tolerance. For $\beta_{3}<3.6$ complex multicellular life had to appear first before the Cambrian era. For $\beta_{3}>3.6$ a perturbation in environmental conditions is necessary to force the appearance of complex multicellular life in the Cambrian. For $\beta_{3}>16$ eucaryotes and complex multicellular life would appear simultaneously. Another important result is that for $\beta_{3}>6.38$ complex multicellular life cannot appear spontaneously but only due to cooling events, because the Earth surface temperature always remains above the upper temperature tolerance of $30^{\circ} \mathrm{C}$ for complex multicellular life.

In contrast to the Neoproterozoic, in the future there will be no bistability for values $\beta_{3}<5$, i.e. the extinction of complex multicellular life will not proceed as an implosion (in comparison to the Cambrian explosion). Our results refine the predictions of Ward and Brownlee (2002).
To analyze the influence of the upper temperature tolerance for complex multicellular life $\left(T_{\max , 3}\right)$ on the life span in more detail we performed additional simulations for $18.6^{\circ} \mathrm{C} \leq T_{\max , 3} \leq 55^{\circ} \mathrm{C}$ for case 2 . For $T_{\max , 3}<18.6^{\circ} \mathrm{C}$ no Cambrian explosion could appear. In all other cases the biotic enhancement factor $\beta_{3}$ is adjusted to reproduce the Cambrian explosion at the right time $542 \mathrm{Myr}$ ago. For $T_{\max , 3}>30^{\circ} \mathrm{C}$ the ultimate life span stays almost constant at $1.6 \mathrm{Gyr}$ from present. This is shown in Fig. 5. An investigation of the influence of $p_{\min }$ on the ultimate life span resulted an extension of only $100 \mathrm{Myr}$ for a minimum $\mathrm{CO}_{2}$ pressure for photosynthesis of $1 \mathrm{ppm}$ in case 1 , while in case 2 the life span was extended only by $20 \mathrm{Myr}$.

The diverse causes of the future biosphere extinction can also be derived from the so-called "terrestrial life corridor" $\left(\mathrm{TLC}_{i}\right.$ ) for the different life forms:

$\mathrm{TLC}_{i}:=\left\{\left(p_{\mathrm{CO}_{2}}, T_{s}\right) \mid \Pi_{i}\left(p_{\mathrm{CO}_{2}}, T_{s}\right)>0\right\}$.

In Fig. 6 we show the atmospheric carbon dioxide content (black line) over time from the Archaean up to the longterm future for the three types of biosphere for case 1 . In the non-coloured region of Fig. 5 no biosphere may exist because of inappropriate temperature or atmospheric carbon dioxide content. The coloured domain is the cumulative TLC for the three biosphere pools in analogy to Fig. 2b. Again we can see that complex multicellular life and eucaryotes become extinct in about $0.8 \mathrm{Gyr}$ and $1.3 \mathrm{Gyr}$, respectively, because of inappropriate temperature conditions. The procaryotes become extinct in about $1.6 \mathrm{Gyr}$ because 

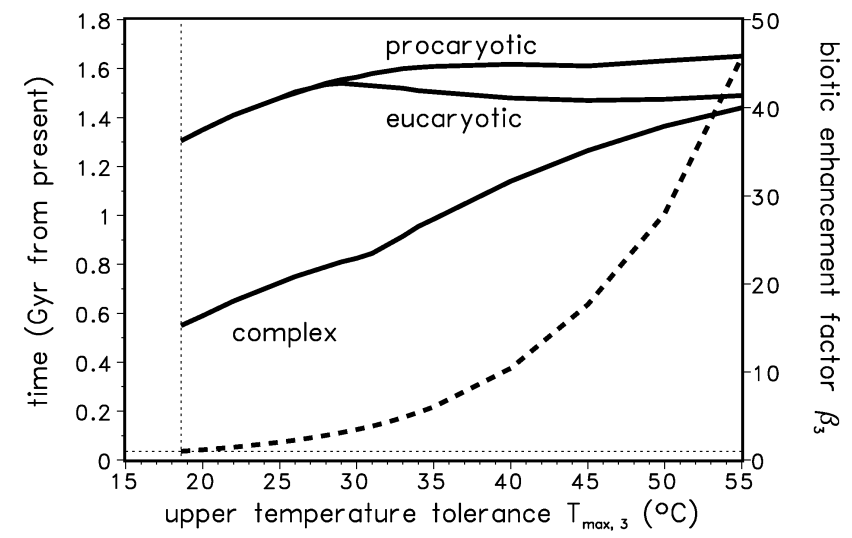

Fig. 5. Life spans of procaryotic, eucaryotic, and complex multicellular life as a function of the upper temperature tolerance of complex multicellular life, $T_{\max , 3}$, for case 2 . The bold dashed line denotes the necessary biotic enhancement factor, $\beta_{3}$, to adjust the Cambrian explosion time. Note, that for $T_{\max , 3}<18.6^{\circ} \mathrm{C}$ (vertical dotted line) no Cambrian explosion can appear.

of achieving the minimum value for atmospheric $\mathrm{CO}_{2}$ content. Our estimation is valid only for photosynthesis-based life. Other life forms like chemolithoautotrophic hyperthermophiles may extend the ultimate life span.

\section{Conclusions}

Procaryotes, eucaryotes, and complex multicellular life forms will become extinct in reverse sequence of their appearance. This is a quantitative manifestation of the qualitative predictions of Ward and Brownlee (2002). We have shown that nonlinear interactions in the biosphere-geosphere system cause bistability during the Neo- and Mesoproterozoic era. For realistic values of the biotic enhancement of weathering there is no bistability in the future solutions for complex life. Therefore, complex organisms will not become extinct by an implosion (in comparison to the Cambrian explosion). Eucaryotes and complex life become extinct because of too high surface temperatures in the future. The time of extinction is mainly determined by the upper temperature tolerance limit of these life forms. The ultimate life span of the biosphere is defined by the extinction of procaryotes in about $1.6 \mathrm{Gyr}$ because of $\mathrm{CO}_{2}$ starvation. Only in a small fraction (1.3-1.7 Gyr) of its habitability time (6.2 Gyr) can our home planet harbour advanced life forms.

However, humankind could extend its life time on Earth by geoengineering (Hoffert et al., 2002). For example, a large mirror at the Lagrange point $\mathrm{L}_{1}$ of the Sun-Earth system could deflect partly the solar flux and stabilize the future climate (Covindasamy and Caldeira, 2000).

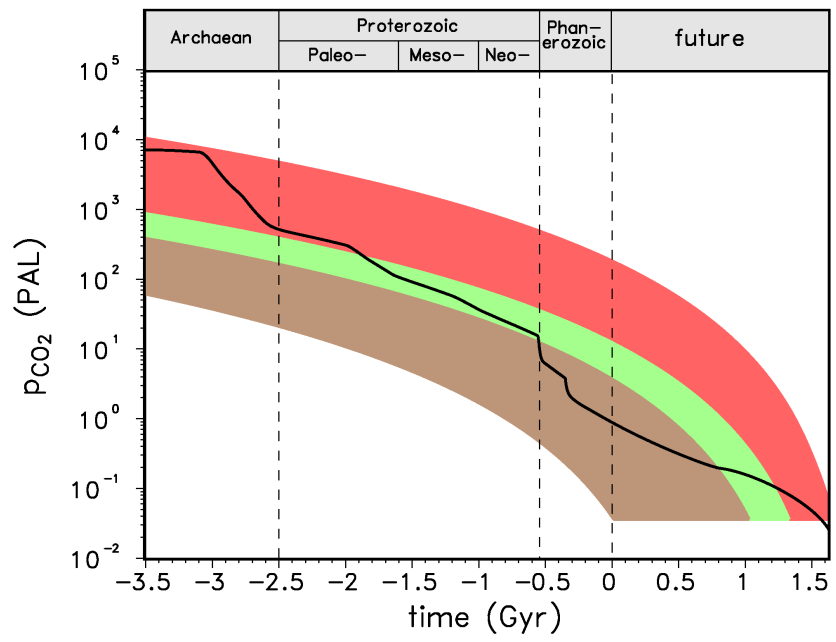

Fig. 6. The evolution of atmospheric $\mathrm{CO}_{2}$ concentration in units of present atmospheric level (PAL) (black line) for case 1. The brown + green + red coloured region defines the terrestrial life corridor (TLC) for procaryotes. The green + brown coloured region defines the TLC for procaryotes and eucaryotes in coexistence. The brown coloured region is the TLC where all three biosphere types may exist together.

Acknowledgements. We want to thank T. Lenton and an anonymous reviewer for the constructive remarks. This work was supported by the German Science Foundation (DFG, grant number Fr 910/10-3), and the University Science Program (HWP, grant number 24\#2597-04/333)

Edited by: F. Westall

\section{References}

Bounama, C., Franck, S., and von Bloh, W.: The fate of Earth's ocean, Hydrol. Earth Syst. Sci., 5, 569-575, 2001.

Caldeira, K. and Kasting, J. F.: The life span of the biosphere revisited, Nature, 360, 721-723, 1992.

Condie, K. C.: Growth and accretion of continental crust: inferences based on Laurentia, Chem. Geol., 83, 183-194, 1990.

Covindasamy, B. and Caldeira, K.: Geoengeneering Earth's radiation balance to mitigate $\mathrm{CO}_{2}$-induced climate change, Geophys Res. Lett., 27, 2141, 2000.

Franck, S. and Bounama, C.: Effects of water-dependent creep rate on the volatile exchange between mantle and surface reservoirs, Phys. Earth Planet. Inter., 92, 57-65, 1995.

Franck, S., Block, A., von Bloh, W., Bounama, C., Schellnhuber, H.-J., and Svirezhev, Y.: Reduction of biosphere life span as a consequence of geodynamics, Tellus, 52B, 94-107, 2000.

Franck, S., Kossacki, K. J., von Bloh, W., and Bounama, C.: Longterm evolution of the global carbon cycle: Historic minimum of global surface temperature at present, Tellus, 54B, 225-343, 2002.

Hoffert, M. I., Caldeira, K., Benford, G., Criswell, D. R., Green, C., Herzog, H., Jain, A. K., Kheshgi, H. S., Lackner, K. S., Lewis, J. S., Lightfoot, H. D., Manheimer, W., Mankins, J. C., Mauel, M. 
E., Perkins, L. J., Schlesinger, M. E., Volk, T., and Wigley, T. M. L.: Advanced technology path to global climate stability: energy for a greenhouse planet, Science, 298, 981-987, 2002.

Hoffman, P. F. and Schrag, D. P.: The snowball Earth hypothesis: testing the limits of global change, Terra Nova, 14(3), 129-155, 2002.

Kasting, J. F., Whitmire, D. P., and Reynolds, R. T.: Habitable zones around main sequence stars, Icarus, 101, 108-128, 1993.

Knauth, L. P. and Lowe, D. R.: High Archean climatic temperature inferred from oxygen isotope geochemistry of cherts in the 3.5 Ga Swaziland Supergroup, South Afrika, GSA Bulletin, 115(5), 566-580, 2003.

Lenton, T. M.: Land and ocean carbon cycle feedback effects on global warming in a simple Earth system model, Tellus, 52B, 1159-1188, 2000.

Lenton, T. M. and von Bloh, W.: Biotic feedback extends the life span of the biosphere, Geophys. Res. Lett., 28(9), 1715-1718, 2001.
Lovelock, J. E. and Whitfield, M.: The life span of the biosphere, Nature, 296, 561-563, 1982.

Schidlowski, M.: Quantitative evolution of global biomass through time: Biological and geochemical constraints, in: Scientists on Gaia, edited by: Schneider, S. H. and Boston, P. J., MIT Press, Cambridge, 211-222, 1991.

Schwartzman, D. W.: Life, temperature and the Earth: The selforganizing biosphere, Columbia University Press, New York, 1999.

Sleep, N. H. and Hessler, A. M.: Weathering of quartz as an Archean climatic indicator, Earth Planet. Sci. Lett., 241, 594602, 2006

Unsöld, A.: Der Neue Kosmos, Springer, Berlin, 1967.

Von Bloh, W., Bounama, C., and Franck, S.: Cambrian explosion triggered by geosphere-biosphere feedbacks, Geophys. Res. Lett., 30(18), 1963, doi:10.1029/2003GL017928, 2003.

Ward, P. and Brownlee, D.: The life and death of planet Earth, Piatkus, London, 2002. 